\title{
Preface: the era of eco-austerity
}

Like a winter dawn creeping chill and grey over the land, the realization is growing that we are entering a new era. While the people of the world have endured previous periods of economic hardship, the new era is different.

There is a real and justified fear as communities seek to comprehend the new language of crisis with its sub-prime borrowers, toxic assets, negative equity and quantitative easing, and somehow to trace cause and effect from the urban poor of America to the glittering bonus payments of the City of London. Factories and offices are closing their doors. It feels like the whole world economy has frozen solid with fear: investment has ground to a halt, sales have crumbled into bare minimalism, nobody is recruiting and nobody is selling a house. There is a collective holding of the breath while we wait for things to get back to normal.

Only they will not go back to normal, if normal is what we have experienced in the last 20 years or so. This really is a new era. For a start, it will take many years to recover the losses of the last 12 months that have been witness to wealth destruction on an unprecedented scale. More fundamentally, we cannot allow a repetition of the fevered bubble of speculation upon which our economic lives floated - because in the end all bubbles burst.

At the same time, the environmental challenges have not gone away. In fact, with every passing of a new scientific report or research project the evidence continues to accumulate: not only are things worse than we thought, they are also getting worse even more quickly than we thought. It is not just climate change. It is an entire package of disasters that threatens our very social existence that scientists are seriously discussing now. Be it water shortages or the decline in petroleum production, encroaching deserts or the loss of forests, species extinction or the collapse of fish stocks - everywhere the pressure of humanity on the planet is reaching critical levels. Until recently, we believed that we could face these challenges and had the economic power to overcome them, because we could afford to be green. Well, we don't have the money any more, but we cannot afford not to be green.

For us, this becomes a critical juncture in human history. A burgeoning global population is going to face a devastating economic slowdown at a time when the resource base is stretched to its limits. 
The era of eco-austerity sounds grim, and well it might be if we are not careful and imaginative. There is a very real danger that, under these circumstances, our future is one of an unremitting scramble for the dwindling resources of the planet. It is all too easy for a 'green totalitarianism' to emerge promising stronger government for a greener planet. An alternative scenario might be one of social implosion and global population collapse as we virtually return to the Stone Age. The truth is that none of us forecasters and analysts and visionaries really knows what the future will bring, because the rules have changed such that the old certainties have crumbled to dust around us.

Governments are currently focused on trying to salvage what they can from the wreckage of the economy, and particularly the financial system. Large sums of money are being poured into vulnerable sectors like banking and the automotive industry in an attempt to return to the 'growth' that was a key factor behind the problems in the first place. This reaction is inevitable, but ultimately may be pointless or counter-productive - just pouring good money after bad.

The era of eco-austerity is opening with a firestorm of creative destruction, which in turn creates the conditions for a radical transformation of our lives. The financial crisis has exposed the chronic lack of sustainability in our previous lifestyles, when we lived like there was no tomorrow - but tomorrow then arrived. Crises have always been the basis for opportunity, and now this is the case more than ever. The new era of eco-austerity may actually be one to be embraced and celebrated rather than confronted and overcome because now is the time for a radical change in our culture, in our social structures, in our political processes, in our lifestyles, in the very meaning of 'wealth' and 'success' and 'growth'.

Over the next few months and years, the shape of the new era will start to become evident. On the other hand, it is extremely challenging to translate this rhetoric into substantive action, particularly in an industry as problematic as the automotive industry and an activity as problematic as motorized personal mobility. This book is a modest attempt to provide an account of how we arrived at this point, and what the solutions might be. In so doing, the book has recourse to some key themes including diversity, flexibility, volatility, turbulence, localism, technological innovation, social and business innovation, and cultural change. Ultimately this is not about the search for the best single technology for a sustainable car - it is much more wide ranging than that. This book is about the search for and transition to multiple and diverse solutions to the provision of sustainable personal mobility. 